\title{
EDUCAÇÃO AMBIENTAL NOS ANOS INICIAIS DO ENSINO \\ FUNDAMENTAL EM ESCOLAS PÚBLICAS URBANAS DO OESTE DO \\ PARANÁ
}

\section{ENVIRONMENTAL EDUCATION IN THE URBAN PUBLIC ELEMENTARY SCHOOL IN WEST OF PARANÁ}

\author{
Josiane Antonina Spielmann Ferronatto ${ }^{1}$ \\ Dirce Conorado Prestes ${ }^{2}$ \\ Eduarda Maria Schneider ${ }^{3}$ \\ Rejane Barbosa de Oliveira ${ }^{4}$
}

\begin{abstract}
Resumo: A Política Nacional de Educação Ambiental (PNEA) postula que a Educação Ambiental (EA) deve ser trabalhada de forma permanente e interdisciplinar. Assim, o objetivo deste trabalho foi verificar se as ações de EA desenvolvidas nas escolas de um município do estado do Paraná seguem as diretrizes do PNEA, e quais vertentes da EA estão sendo trabalhadas com mais frequência. A metodologia de caráter quali-quantitativa consistiu na aplicação de um questionário aos professores de Ciências do Ensino Fundamental Inicial das três escolas urbanas do município. Os resultados mostraram que, para se adaptar ao PNEA, as escolas precisam incluir a EA no período de planejamento dos professores, ampliando os esforços de interdisciplinaridade e incentivar a participação da comunidade. Verificou-se, ainda, que as abordagens Conservacionista e Pragmática são mais empregadas do que a abordagem Crítica, assim, é importante inserir mais ações voltadas para EA Crítica no planejamento curricular, contribuindo para seu desenvolvimento prático.
\end{abstract}

Palavras-chave: Educação Ambiental; PNEA; Ensino de Ciências.

\begin{abstract}
The National Environmental Education Policy (PNEA) postulates that Environmental Education (EE) must be worked in a permanent and interdisciplinary way. Thus, the objective of this work was to verify whether the EE actions developed in schools in a municipality in the Paraná (Brazil) follow the guidelines of the PNEA, and which aspects of the EE are more frequent. The qualitative and quantitative
\end{abstract}

${ }^{1}$ Licenciada em Ciências Biológicas, Universidade Tecnológica Federal do Paraná (UTFPR). Universidade Tecnológica Federal do Paraná (UTFPR), Santa Helena, Paraná, Brasil. E-mail: jo_spielmann@hotmail.com

${ }^{2}$ Mestranda, Programa de Pós-graduação em Recursos Naturais e Sustentabilidade da Universidade Tecnológica Federal do Paraná (UTFPR). Programa de Pós-graduação em Recursos Naturais e Sustentabilidade da Universidade Tecnológica Federal do Paraná (UTFPR), Santa Helena, Paraná, Brasil. E-mail: dirceprestes12@gmail.com

${ }^{3}$ Docente, Programa de Pós-graduação em Recursos Naturais e Sustentabilidade da Universidade Tecnológica Federal do Paraná, (UTFPR). Programa de Pós-graduação em Recursos Naturais e Sustentabilidade da Universidade Tecnológica Federal do Paraná, (UTFPR), Santa Helena, Paraná, Brasil. E-mail: emschneider@utfpr.edu.br

${ }^{4}$ Docente, Programa de Pós-graduação em Recursos Naturais e Sustentabilidade da Universidade Tecnológica Federal do Paraná, (UTFPR). Programa de Pós-graduação em Recursos Naturais e Sustentabilidade da Universidade Tecnológica Federal do Paraná, (UTFPR), Santa Helena, Paraná, Brasil. E-mail: rboliveira@utfpr.edu.br 
DOI: https://doi.org/10.33238/ReBECEM.2020.v.4.n.2.24137

methodology consisted of the application of a questionnaire to teachers of Sciences of the Elementary Education of the three urban schools. The results showed that, in order to adapt to the PNEA, schools need to include $\mathrm{EE}$ in the planning period of teachers, expanding interdisciplinary efforts and encouraging community participation. It was also verified that the Conservationist and Pragmatic approaches are more used than the Critical approach, therefore, it is important to insert more actions focused on Critical EE in the curricular planning, contributing to its practical development.

Keywords: Environmental Education; PNEA; Elementary School.

\section{Introdução}

A degradação ambiental em larga escala tem como marco a Revolução Industrial do século XVIII, que tinha como foco a produtividade e o crescimento econômico, sem considerar a geração de poluentes e a limitação dos recursos naturais. Como consequência, ocorreu a superprodução e o consumo excessivo, acarretando na contaminação de rios, poluição do ar, desmatamento florestal, vazamento de produtos químicos prejudicais à saúde e perda de milhares de vidas (AVILA; LINGNAU, 2015).

Contudo, os debates acerca da qualidade do meio ambiente foram ganhando força apenas no final dos anos 1960, impulsionados por uma série de desastres ambientais. Dentre estes, pode ser citado o Smog em Londres ocorrido em 1952, resultante da queima de carvão de baixa qualidade. Esse evento também conhecido como "A Névoa Matadora", foi responsável pela morte de quatro mil pessoas, principalmente devido a problemas respiratórios causados pela fumaça da queima do carvão. Como resultado, foi promulgada a Lei do Ar Limpo na Inglaterra. Outro exemplo foi o caso da contaminação da água do mar por mercúrio na Baía de Minamata em 1956 no Japão, onde foram registradas 107 mortes oficiais e quase três mil casos em verificações (POTT; ESTRELA, 2017). Contribuiu ainda para as discussões a publicação do livro da bióloga Rachel Carson, intitulado "Primavera Silenciosa" (1969), que alertou para o aumento do uso indiscriminado de pesticidas, resultando na proibição do uso do defensivo agrícola DDTDicloro-Difenil-Tricloroetano nos EUA (BONZI, 2013).

Após esses desastres e alertas, a Organização das Nações Unidas (ONU) realizou diversos eventos com o objetivo de discutir as questões ambientais. O primeiro desses eventos ocorreu no ano de 1972 na cidade de Estocolmo na Suécia, e ficou conhecido como "Conferência da ONU sobre o Meio Ambiente Humano". Tal conferência estabeleceu um Plano de Ação Mundial para o meio Ambiente e recomendou para os países signatários o estabelecimento de planos de Educação Ambiental (EA). Assim, a EA passou a ser considerada como campo de ação pedagógica, adquirindo relevância e 


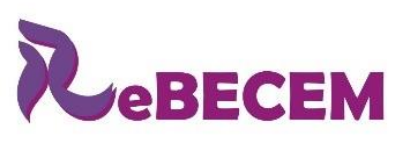

Revista Brasileira de Educação em

Ciências e Educação Matemática

DOI: https://doi.org/10.33238/ReBECEM.2020.v.4.n.2.24137

vigências internacionais. Os princípios da EA foram formalizados mais tarde, em 1975, durante a Conferência de Belgrado em um documento que ficou conhecido como a Carta de Belgrado. Essa carta trazia como princípio fundamental a necessidade de uma nova ética global que proporcionasse a erradicação da pobreza, da fome, do analfabetismo, da poluição e da dominação e exploração humanas. Além disso, postulou que a EA deve ser contínua, multidisciplinar, integrada às diferenças regionais e voltada para os interesses nacionais (POTT; ESTRELA, 2017).

Com o objetivo de ampliar as discussões ocorridas em Belgrado, o Programa das Nações Unidas para o Meio Ambiente (PNUMA) e a UNESCO promoveram em 1977 a Primeira Conferência Intergovernamental sobre Educação Ambiental em Tbilisi (Geórgia). Essa conferência resultou em um documento conhecido como a Declaração de Tbilisi, a qual propôs que: "a EA deve dirigir-se às pessoas de todas as idades, a todos os níveis, na educação formal e não-formal”. Adicionalmente, a Conferência de Tbilisi estabeleceu como objetivos da EA fazer com que os indivíduos e a coletividade: 1) compreendam a natureza complexa do meio ambiente, resultante da interação entre seus aspectos físicos, biológicos, culturais, sociais e econômicos; 2) adquiram conhecimentos, valores, comportamentos e habilidades práticas para participar, de maneira responsável e eficaz, da prevenção e da solução dos problemas ambientais, bem como da gestão da questão da qualidade do meio ambiente (DIAS, 1998).

Para dar continuidade às discussões sobre as questões ambientais, a ONU criou em 1983 a Comissão Mundial sobre o Meio Ambiente e Desenvolvimento (CMMAD). A CMMAD foi presidida por Gro Harlem Brundtland, que na época era a Primeira Ministra da Noruega. A CMMAD tinha como objetivo reexaminar as questões críticas do meio ambiente e desenvolvimento discutidas na Conferência de Estocolmo. Essa comissão deveria elaborar uma nova compreensão do problema ambiental, em especial a questão da limitação dos recursos naturais, e propor novas formas de cooperação internacional que pudessem orientar políticas e ações internacionais. Como resultado do trabalho dessa comissão, foi lançado na forma de livro o relatório "Nosso Futuro Comum", também conhecido como relatório Brundtland (DIAS, 1998).

O relatório Nosso Futuro Comum mostrou a necessidade de um novo modelo de desenvolvimento capaz de manter o progresso em todo o planeta a longo prazo. Esse novo modelo foi chamado de: “desenvolvimento sustentável”, o qual ficou definido como: "o desenvolvimento capaz de suprir as necessidades da geração atual, sem comprometer a 
DOI: https://doi.org/10.33238/ReBECEM.2020.v.4.n.2.24137

capacidade de atender às necessidades das futuras gerações" (TRAJBER; SORRENTINO, 2007).

Para discutir o desenvolvimento sustentável, foi realizada em 1992 no Rio de Janeiro a Conferência das Nações Unidas sobre Meio Ambiente e Desenvolvimento, mais conhecida como Rio-92, a qual legou ao mundo uma série de documentos hoje considerados fundamentais para a promoção do desenvolvimento sustentável: a Declaração do Rio sobre Ambiente e Desenvolvimento, Declaração dos Princípios das Florestas, a Carta da Terra, a Agenda 21 e três Convenções Internacionais sobre Diversidade Biológica, Mudança do Clima e Combate à Desertificação (DIAS, 1998). Muitos desses documentos e conferências formaram as bases para as políticas nacionais brasileiras, incluindo a Política Nacional de Educação Ambiental (PNEA) publicada em 1999.

Dez anos após a realização da Rio-92, foi realizada Rio+10 em Joanesburgo (África do Sul). A Rio+10 tinha como objetivos avaliar o progresso dos acordos estabelecidos na Rio-92 e da implantação da Agenda 21. Em 2012, foi realizada a Rio+20, novamente na cidade do Rio de Janeiro (Brasil). Essa conferência teve como tema principal a Economia Verde, baseada nos conceitos de Biocapacidade e Pegada Ecológica. Uma das principais metas da Economia Verde é diminuir a Pegada Ecológica dos países, especialmente através da diminuição das emissões de carbono, por meio da implantação de uma nova matriz energética. Além disso, foram discutidos na Rio+20 a implantação do pagamento por serviços ambientais e a renovação do compromisso político para o desenvolvimento sustentável. Das discussões da Rio+20 resultou o documento: "O Futuro que Queremos"; no qual ficou acordado que o desenvolvimento sustentável seria alcançado através da Economia Verde. Além disso, o documento lançou as bases dos Objetivos do Desenvolvimento Sustentável (ODS), mas estes somente se consolidaram em 2015, quando foi lançada a Agenda 2030 (GUIMARÃES; FONTOURA, 2012; SAWYER, 2011). Desde então, a EA vem caminhando para se tornar uma Educação para o Desenvolvimento Sustentável. Perante tal histórico mundial do desenvolvimento da EA cabe compreender como ela vem sendo implantada no contexto escolar brasileiro.

\section{Educação Ambiental no contexto escolar}




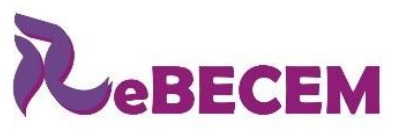

Revista Brasileira de Educação em

Ciências e Educação Matemática

DOI: https://doi.org/10.33238/ReBECEM.2020.v.4.n.2.24137

No Brasil, desde a Rio-92, a EA vem sendo vista como instrumento fundamental para alcançar o desenvolvimento sustentável. Nesse sentido, foi promulgada a Lei $\mathrm{n}^{\circ}$ 9.795 de 27 de abril de 1999, conhecida como Política Nacional de Educação Ambiental (PNEA). A PNEA define por Educação Ambiental “os processos pelos quais o indivíduo e a coletividade edificam valores sociais, conhecimentos, habilidades, atitudes e competências direcionadas para a conservação do meio ambiente, recurso de uso comum do povo, essencial para a qualidade da vida e sua sustentabilidade" (BRASIL, 1999). O documento estipula, ainda, a EA como um componente essencial e duradouro da educação nacional, devendo ser existente, de forma planejada, em todos os níveis e modalidades do processo educativo, em caráter formal e não formal (PRONEA, 2014). Entende-se por EA formal aquela ensinada nas escolas, em todos os níveis do ensino, enquanto a EA não formal é entendida como as ações e práticas educativas voltadas aos impactos da coletividade relacionadas às questões ambientais e sua organização e participação na defesa da qualidade do meio ambiente, realizadas fora da esfera do ensino escolar obrigatório.

Neste trabalho, focaremos a EA formal. Esta deve ser implantada já no começo da atividade escolar. Nessa perspectiva, a temática da EA requer uma metodologia pedagógica interdisciplinar, devido à complexidade das relações existentes entre os conceitos de natureza, meio ambiente, ecologia e suas interações com a sociedade (TRAJBER; SORRENTINO, 2007). Porém, as abordagens sobre a EA no ambiente escolar muitas vezes se concentram apenas na área das Ciências ou Biologia, sem considerar as demais disciplinas, que são importantes para o entendimento de toda a complexidade social e cultural dos problemas ambientais (DIAS; BOMFIM, 2011). Com os conteúdos ambientais permeando todas as disciplinas do currículo e contextualizados com a realidade da comunidade, a escola ajudará o aluno a perceber a correlação dos fatos e a ter uma visão integral do mundo em que vive. Para isso, a EA deve ser abordada de forma sistemática e transversal, em todos os níveis de ensino, assegurando a presença da dimensão ambiental de forma interdisciplinar nos currículos das diversas disciplinas e das atividades escolares, conforme orienta a PNEA (AVILA; LINGNAU, 2015, p.25).

O trabalho interdisciplinar da EA poderá ser desenvolvido mediante um esforço conjunto dos atores escolares na sensibilização dos alunos sobre o ambiente no qual a escola está inserida. Esse esforço deverá ser feito de tal modo que leve os alunos a relacionar os problemas ambientais com a realidade de suas comunidades, para que os mesmos possam perceber a problemática no mundo real. Assim, a escola será um 
DOI: https://doi.org/10.33238/ReBECEM.2020.v.4.n.2.24137

ambiente social, onde o aluno terá sua atenção despertada para os problemas ambientais, garantindo que este coloque em prática todas as aprendizagens recebidas (REIS; SEMÊDO; GOMES, 2012).

Sendo assim, no cenário educacional brasileiro a EA não se propõe como uma nova disciplina, mas sim como um processo de aprendizagem permanente que deve ser desenvolvido de forma interdisciplinar em todos os níveis de ensino de forma que os indivíduos adquiram conhecimentos, valores e competências para atuar e tomar decisões responsáveis frente aos problemas ambientais. Perante tal compreensão, este trabalho propõe investigar a EA nos anos iniciais do Ensino Fundamental.

\section{Educação Ambiental nos Anos Iniciais do Ensino Fundamental}

A questão ambiental na visão da maioria da população ainda se simplifica nos temas trabalhados e associados pela mídia, como o efeito estufa, camada de ozônio, aquecimento global, desmatamento da Amazônia, etc. Esse trabalho realizado pela mídia ajuda a atrair certa atenção para as questões ambientais, mas são insatisfatórios para formação de novas atitudes, pois a mudança somente ocorrerá pela participação cidadã. A formação para a cidadania deve ocorrer ao longo de toda a vida escolar, mas especialmente nas séries iniciais, visto que, quanto mais cedo o aluno adquirir capacidade de participação, valores e habilidades voltadas para a questão ambiental, maior será a sua participação na sociedade (DIAS; BOMFIM, 2011).

Medeiros et al., (2011) confirmam a importância de se iniciar logo nos primeiros anos de escolaridade o ensino da EA pois, segundo esses autores, é nesse estágio do desenvolvimento humano que se inicia o processo de formação da personalidade e o despertar para a cidadania, havendo a formação de cidadãos que se preocupam com o meio ambiente hoje e para as futuras gerações. Os autores ressaltam, ainda, que para que haja um mundo justo e equilibrado, é necessário haver uma interação entre educadores e educandos para que possa haver transformações nas formas de se utilizarem os recursos disponíveis na natureza sem que haja agressões e que esses recursos possam estar sempre disponíveis no futuro.

A EA trabalhada nas séries iniciais do ensino fundamental possibilita preservação do ambiente e na melhor qualidade de vida, quando, desde cedo, o aluno aprende o valor dos recursos naturais, e que pequenas ações conscientizadas podem fazer muita diferença se somadas com de outros cidadãos. 


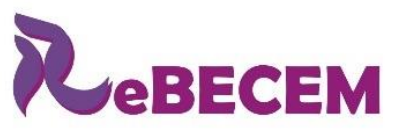

Revista Brasileira de Educação em

Ciências e Educação Matemática

DOI: https://doi.org/10.33238/ReBECEM.2020.v.4.n.2.24137

Assim, percebe-se que a escola é um lugar privilegiado para aprendizagens, com dificuldades e desafios. Contudo, trabalhar EA em qualquer escola é um grande desafio, pois é necessária a presença da EA nas estruturas curriculares, de modo que se promova uma contínua mudança na mentalidade, estimulando no ser humano uma consciência sobre o meio ambiente e favorecendo a construção de um lugar habitável para as futuras gerações (FERREIRA; PEREIRA; BORGES 2013).

Confirma-se, assim, a defesa para se trabalhar a EA desde os primeiros anos da escolaridade. Contudo, para a eficácia das ações de EA é necessário que os profissionais que irão desenvolvê-la tenham ciência da amplitude que as questões ambientais abrangem e, assim, que fundamentem estas atividades para que elas realmente contribuam para uma mudança de atitude dos indivíduos quanto ao meio ambiente. É necessário então compreender as vertentes das ações de EA.

\section{Vertentes da Educação Ambiental}

Podem ser reconhecidas múltiplas vertentes da EA, cada uma com conceitos, práticas e metodologias próprias, mas nem sempre evidentes. Entre elas, podem ser citadas as três mais evidentes nas práticas da EA: Conservacionista, Pragmática e Crítica. Mas, mesmo com tantas denominações, para o público não especializado, a EA é trabalhada e compreendida apenas como uma única vertente, cujo objetivo é conscientizar as pessoas em relação a problemas estritamente ecológicos, o que é uma visão equivocada (SANTOS; TOSCHI, 2015).

A EA Conservacionista surgiu de uma lógica do pensamento humano para com a natureza, com as destruições naturais e uma preocupação em educar para conservar. Esta vertente vem sendo empregada desde as primeiras discussões sobre o meio ambiente a partir da década de 1960, especialmente após as Conferências de Estocolmo, Belgrado e Tbilisi. A vertente Conservacionista vem sendo aplicada principalmente para crianças do Ensino Fundamental, com as quais é trabalhado o amor pela natureza, especialmente em Unidades de Conservação e em atividades de ecoturismo. Dentro da lógica Conservacionista, acredita-se que, ao se transmitir o conhecimento correto, o indivíduo compreenderá a problemática ambiental e consequentemente mudará seu comportamento. Além disso, essa vertente privilegia vários aspectos em detrimento dos realmente importantes, tais como: a teoria sobre a prática, o indivíduo sobre a sociedade e o tecnicismo sobre a política. Para Santos e Toschi (2015), o fato de essa vertente 


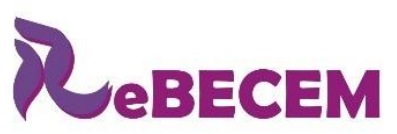

Revista Brasileira de Educação em

Ciências e Educação Matemática

DOI: https://doi.org/10.33238/ReBECEM.2020.v.4.n.2.24137

almejar apenas mudanças de comportamento, a torna ineficaz, pois não haverá mudanças efetivas se não houver transformação nos sistemas econômico e político da sociedade.

A EA Conservacionista engloba o conjunto de práticas nas quais é valorizada a dimensão afetiva na relação do homem com a natureza, buscando a solução da crise ambiental na ausência de questionamentos políticos, valorizando a mudança de comportamentos e atitudes individuais, tendo por base a ecologia profunda, exaltando um esclarecimento sobre a estrutura e o funcionamento dos sistemas ecológicos. Esta vertente foi dominante até 1990, quando surgiu a vertente Pragmática. Mas, mesmo não sendo mais dominante, a EA Conservacionista ainda é encontrada nos meios de ensino da EA nos dias de hoje, seja de forma isolada, ou mesclada às outras vertentes (CAMPOS, 2015).

A EA Pragmática busca uma solução para a crise socioambiental nos próprios referenciais causadores da crise. Essa vertente está relacionada ao conceito de desenvolvimento sustentável, e trabalha a ideia de que a natureza pode e deve ser utilizada em benefício econômico e social da humanidade, pregando que somos capazes de usufruir dos recursos naturais sem causar impactos negativos ao meio ambiente. Esta vertente vem ganhando força desde a definição de desenvolvimento sustentável no relatório "Nosso Futuro Comum”, e se acentuou após as discussões sobre Economia Verde na Rio+20. Com o lançamento dos Objetivos do Desenvolvimento Sustentável na Agenda 2030, a EA está tendendo a ser chamada de Educação para o Desenvolvimento Sustentável (EDS). Contudo, muitos autores veem diferenças significativas nos conceitos de EA e EDS, sendo esta última intrinsecamente relacionada às práticas da EA Pragmática (SILVA; TEIXEIRA, 2019).

A EA Pragmática tem como lógica a capacidade de resolver os problemas ambientais com ações individuais. Sobre isso, Campos (2015) discute que a EA Pragmática faz uma leitura racionalista da crise ambiental, dando extrema relevância para questões como: reciclagem, energias limpas e pegada ecológica sem realizar, no entanto, um aprofundamento político. Para esse autor, essa vertente propõe uma Educação para o Desenvolvimento Sustentável e para o Consumo Sustentável, mas sem uma discussão sociopolítica sobre o que seria sustentabilidade, sendo, portanto, uma forma de ação conveniente à ideologia capitalista hegemônica (CAMPOS, 2015).

Já a EA Crítica se baseia em um entendimento mais amplo da participação social do cidadão como prática indispensável à democracia e à emancipação socioambiental. Neste contexto, a democracia está voltada para a construção de uma sustentabilidade que exige uma mudança em relação à natureza, ao homem e à Terra (DIAS; BOMFIM, 2011). 


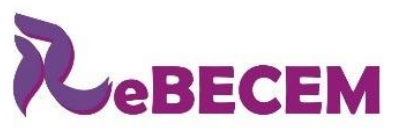

Revista Brasileira de Educação em

Ciências e Educação Matemática

DOI: https://doi.org/10.33238/ReBECEM.2020.v.4.n.2.24137

De acordo com Santos e Toschi (2015), o trabalho da EA Crítica deve ser o de contribuir para a formação de um cidadão ecológico, através de mudanças de valores e atitudes, reorganizando as maneiras de convivência no coletivo e individual. A educação não deve ser reduzida ao indivíduo e nem a coletivos em uma visão abstrata, mas sim levar a uma reflexão sobre as relações do indivíduo com a sociedade, pois ambos só têm sentido se pensados conjuntamente. Dessa forma, a vertente Crítica reconhece a dimensão histórica da questão ambiental e a indissociabilidade dos aspectos sociais da EA, assumindo que esta está além de aspectos comportamentais do indivíduo. Para isso, a EA Crítica faz reflexões sobre o modelo econômico capitalista e aos atuais padrões de consumo e produção. Ressalta a importância da cidadania participativa, dos movimentos sociais e da diagnose de impactos ambientais locais, bem como da responsabilidade industrial e governamental para resolução de problemas ambientais (CAMPOS, 2015).

Diante do exposto acima, este estudo tem como objetivo avaliar se a EA está sendo implantada nas escolas do Ensino Fundamental Anos Iniciais do município pesquisado de acordo com os princípios da PNEA, e quais vertentes da EA estão sendo trabalhadas com mais frequência nessas escolas.

\section{Metodologia}

\subsection{Caracterização da área de estudo}

O município no qual a pesquisa foi realizada possui uma área de 758,227 km² e está localizada na região Oeste do estado do Paraná. Segundo dados do IBGE (2019), possui 26.490 habitantes, com a taxa de escolarização de 99,4\% e Índice de Desenvolvimento da Educação Básica (IDEB) dos Anos Iniciais do Ensino Fundamental de 6,7. A área urbana do município em que a pesquisa foi realizada possui três escolas municipais que atendem o Ensino Fundamental Anos Iniciais.

\subsection{Coleta e análise dos dados}

Os dados foram coletados no período de agosto a setembro de 2019, com professores de Ciências do Ensino Fundamental. Escolhemos trabalhar com esses professores por compreender as dificuldades do trabalho interdisciplinar nas escolas devido ao engessamento dos planos de ensino. Assim, a temática ambiental é mais facilmente trabalhada em Ciências, pois o currículo direciona as atividades de EA para 


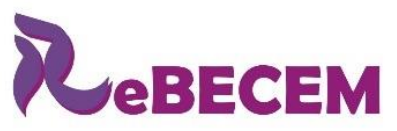

\section{Revista Brasileira de Educação em \\ Ciências e Educação Matemática \\ ISSN 2594-9179}

DOI: https://doi.org/10.33238/ReBECEM.2020.v.4.n.2.24137

essa disciplina. Foram realizados os seguintes procedimentos: solicitação de autorização junto aos diretores e professores de Ciências das três escolas existentes na área urbana para o desenvolvimento da pesquisa, aplicação do questionário aos professores e análise das respostas. Participaram dessa pesquisa sete professores que representavam na época da aplicação 100\% dos professores de Ciências do Ensino Fundamental I efetivos da rede municipal urbana. Destes, quatro haviam assumido recentemente o cargo pelo concurso público, e dois estavam no fim do contrato PSS. Os professores atuantes não são Licenciados em Ciências, suas formações são: magistério e pedagogia. Por questões éticas não foram solicitados os nomes dos profissionais e nem a instituição atuante.

O questionário aplicado possuía 14 questões. As questões 1 a 3 tinham como objetivo verificar se a escola desenvolvia alguma atividade de EA e se essas atividades eram desenvolvidas com apoio de instituições externas (Quadro 1).

Quadro 1: Questões 1 a 3 do questionário aplicado

1. Em sua escola há o desenvolvimento de atividades/projetos que possam ser considerados como de Educação Ambiental?

( ) sim, a escola desenvolve atividades ou projetos de educação ambiental, e essas atividades são elaboradas durante o período de planejamento dos professores;

( ) sim, a escola desenvolve atividades de educação ambiental, mas essas são esporádicas e elaboradas fora do período de planejamento dos professores;

( ) não, a escola não desenvolve atividades ou projetos de educação ambiental, e as únicas abordagens sobre o tema ocorrem durante minhas aulas ou nas aulas de outros colegas;

( ) não, a escola não desenvolve atividades de educação ambiental, e o tema não é abordado durante as minhas aulas.

2. Se a resposta foi sim para a questão anterior, por favor, descreva resumidamente as atividades de educação ambiental desenvolvidas pela escola durante os últimos dois anos:

3. As atividades de educação ambiental desenvolvidas pela escola são, em sua maioria, organizadas pela própria escola, ou são organizadas por instituições externas (ex. Itaipu, Projeto Cultivando Água Boa, Secretaria Municipal do Meio Ambiente, IAP, SANEPAR, Faculdades, Associação de Catadores, empresas, etc.)? Em caso de instituições externa, por favor citar a instituição, o projeto ou atividade realizada.

Fonte: Elaborado pelos autores (2019)

As questões 4 e 5 tiveram como objetivo investigar o público alvo, a participação de toda comunidade escolar ou professores restritos a disciplinas ou turmas (Quadro 2).

Quadro 2: Questões 4 e 5 do questionário aplicado

4. Essas atividades, no geral, abrangem como público-alvo: ( ) apenas os alunos, ( ) os alunos e os professores ou ( ) toda a comunidade escolar.

5. Essas atividades de educação ambiental normalmente envolvem: ( ) todos os professores da escola; ( ) todos os professores de uma determinada turma; ( ) apenas os professores de Ciências; ( ) professores de determinadas disciplinas (especificar):

Fonte: Elaborado pelos autores (2019)

As questões 6 e 7 buscavam informações sobre os temas mais abordados nas atividades e as práticas pedagógicas utilizadas (Quadro 3). 
DOI: https://doi.org/10.33238/ReBECEM.2020.v.4.n.2.24137

Quadro 3: Questões 6 e 7 do questionário aplicado

6. Quais dos temas abaixo você já abordou em suas aulas ou atividades de educação ambiental, e com qual frequência? (escolha quantas achar pertinentes).

( ) preservação de espécies ameaçadas de extinção - ( ) poucas vezes ( ) várias vezes.

( ) biodiversidade - ( ) poucas vezes ( ) várias vezes.

( ) mata atlântica - ( ) poucas vezes ( ) várias vezes.

( ) floresta amazônica - ( ) poucas vezes ( ) várias vezes.

( ) desmatamento - ( ) poucas vezes ( ) várias vezes.

( ) poluição - ( ) poucas vezes ( ) várias vezes.

( ) hortas/plantas medicinais - ( ) poucas vezes ( ) várias vezes.

( ) água/recursos hídricos - ( ) poucas vezes ( ) várias vezes.

( ) Reciclagem de lixo/resíduos sólidos - ( ) poucas vezes ( ) várias vezes.

( ) energias renováveis - ( ) poucas vezes ( ) várias vezes.

( ) sustentabilidade - ( ) poucas vezes ( ) várias vezes.

( ) pegada ecológica - ( ) poucas vezes ( ) várias vezes.

( ) economia verde - ( ) poucas vezes ( ) várias vezes.

( ) consumismo - ( ) poucas vezes ( ) várias vezes.

( ) racismo ambiental - ( ) poucas vezes ( ) várias vezes.

( ) problemas sociais gerados pelo lixo - ( ) poucas vezes ( ) várias vezes.

( ) relação entre problemas ambientais e pobreza - ( ) poucas vezes ( ) várias vezes

( ) relação entre problemas ambientais e saúde - ( ) poucas vezes ( ) várias vezes

( ) relação entre consumismo e problemas ambientais - ( ) poucas vezes ( ) várias vezes

( ) problemas ambientais do município - ( ) poucas vezes ( ) várias vezes.

( )outros:

7. Durantes as atividades de educação ambiental realizadas por você, ou pela escola, quais são as práticas pedagógicas comumente utilizadas:

( ) aulas expositivas

( ) palestras proferidas por convidados externos à escola

( ) apresentação de vídeos (filmes, desenhos, documentários)

( ) confecção com os alunos de material informativo (ex. cartazes, cartilhas, folhetos, etc.)

( ) oficinas

( ) gincanas

( ) aulas práticas

( ) apresentações artísticas (ex. teatros, musicais, etc.)

Fonte: Elaborado pelos autores (2019)

As questões 8 a 10 tiveram o intuito de identificar as oficinas trabalhadas, métodos das gincanas desenvolvidas e aulas práticas (Quadro 4).

Quadro 4: Questões 8 a 10 do questionário aplicado

8. Se você marcou a opção "oficinas", por favor, escolha quais delas foram mais frequentes:

( ) artesanato com lixo reciclável ( ) reciclagem de papel ( ) reutilização de óleo para a fabricação de papel, ( ) construção de hortas, ( ) outras:

9. Se você marcou "gincanas", por favor descreva resumidamente as atividades realizadas pelos alunos:

10. Se você marcou aulas práticas, por favor, descreva resumidamente as atividades realizadas:

Fonte: Elaborado pelos autores (2019)

As questões 11 e 12 relatar as turmas com maior frequência de desenvolvimento de atividades e visitas proporcionadas pela escola referente ao assunto (Quadro 5).

Quadro 5: Questões 11 e 12 do questionário aplicado

11. Para quais anos do Ensino Fundamental as atividades de educação ambiental são realizadas com mais frequência? Por favor, cite o ano e atividade trabalhada com mais frequência. 
DOI: https://doi.org/10.33238/ReBECEM.2020.v.4.n.2.24137

12. Você ou a escola, já levaram os alunos em visitas guiadas para abordar temas da educação ambiental? Se sim, por favor, especifique o local da visita, o tema abordado e quais turmas foram levadas.

\section{Fonte: Elaborado pelos autores (2019)}

E por fim, as questões 13 e 14 pretendiam identificar a existência da interdisciplinaridade da disciplina de Ciências com outras disciplinas e o envolvimento de outros professores (Quadro 6).

Quadro 6: Questões 13 e 14 do questionário aplicado

13. Já houve alguma iniciativa entre você e seus colegas que ministram outras disciplinas para a realização de um projeto ou atividade de educação ambiental em conjunto? Em caso afirmativo, por favor, relate resumidamente a experiência (mesmo que não tenha tido êxito).

14. Faça comentários que você achar pertinentes a respeito das atividades de educação ambiental desenvolvidas pela escola ou por você.

Fonte: Elaborado pelos autores (2019)

A análise dos dados obtidos foi embasada na abordagem quali-quantitativa descritiva. Conforme Flick (2009), os tratamentos qualitativos e quantitativos dos resultados podem ser complementares, enriquecendo a análise e as discussões. Para Bryman (1992), citado por Flick (2009), a lógica da triangulação, ou seja, da combinação entre métodos qualitativos e quantitativos, visa fornecer um quadro mais geral da questão em estudo. Nesta perspectiva, a pesquisa qualitativa pode ser apoiada pela pesquisa quantitativa e vice-versa, possibilitando uma análise estrutural do fenômeno com métodos quantitativos e uma análise processual mediante métodos qualitativos. Sendo assim, na presente pesquisa a análise quantitativa dos dados constituídos foi realizada a partir das respostas agrupadas em planilhas para construção de gráficos de acordo com sua relevância e a análise qualitativa dos resultados foi organizada a partir da categorização e discussão das respostas analisadas a partir da literatura. Este estudo caracteriza-se ainda, de acordo com Gil (2002), como pesquisa descritiva, tendo em vista que tem como objetivo investigar as opiniões da população de professores e descrever as características da EA nas escolas pesquisadas.

\section{Resultados e Discussão}

Todos os professores participantes da pesquisa relataram que há o desenvolvimento de atividades de EA nas escolas. Destes, quatro mencionaram que as atividades são elaboradas durante o planejamento das aulas, exigindo do professor um trabalho de reflexão sobre o ensino aprendizagem. Já os outros três destacaram que desenvolvem as atividades/projetos, mas sem um planejamento inicial, sendo desenvolvidas esporadicamente no andamento das aulas. Vale salientar que dentre esses 


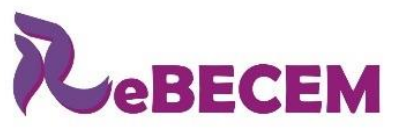

Revista Brasileira de Educação em

Ciências e Educação Matemática

DOI: https://doi.org/10.33238/ReBECEM.2020.v.4.n.2.24137

professores, quatro assumiram recentemente o concurso público no município e tem pouco tempo de atuação, sendo uma possível explicação para esta discrepância.

Esses resultados mostram que é necessário ampliar a inclusão da EA no planejamento escolar, para que essa possa ser inserida no plano de aula dos professores. De acordo com Oliveira (2011), o plano de aula é o principal instrumento didáticopedagógico para o desenvolvimento da atividade docente em seu âmbito escolar. Sendo assim, o plano de aula é o elemento fundamental para a organização das atividades desenvolvidas na sala de aula, onde o professor tem o papel de conciliar qualidade e tempo utilizado na construção de saberes de seus alunos, possibilitando a organização do conhecimento.

Adicionalmente, a elaboração de atividades ou projetos de EA durante o período de planejamento está de acordo com a PNEA (Lei n 9.795 de 1999), a qual em seu Art. $2^{\circ}$ afirma que: "A educação ambiental é um componente essencial e permanente da educação nacional, devendo estar presente, de forma articulada, em todos os níveis e modalidades do processo educativo, em caráter formal e não-formal” (BRASIL, 1999). Ainda na mesma Lei, o Art. $10^{\circ}$ propõe que a "EA deve estar presente em todos os segmentos e níveis da educação formal de maneira que seja desenvolvida com uma prática educativa integrada, contínua e permanente". Dessa forma, para que a EA atenda à referida Lei, é essencial sua inclusão no período de planejamento escolar e nos planos de aulas dos professores.

Na Figura 1, podemos constatar que a EA é trabalhada em todos os anos iniciais do Ensino Fundamental, com a maior frequência das atividades concentradas no terceiro ano. Para compreendermos esse fato, é preciso verificar que nos Parâmetros Curriculares Nacionais (PCN), um dos objetivos do terceiro ano é a valorização da vida em sua diversidade e a conservação dos ambientes; interpretação de situações de equilíbrio e desequilíbrio ambiental, relacionando informações sobre a interferência do ser humano e a dinâmica das cadeias alimentares (BRASIL, 1998). Dessa forma, podemos concluir que no terceiro ano o trabalho com EA é facilitado devido aos temas já estarem inseridos no conteúdo programático e nos livros didáticos. 
DOI: https://doi.org/10.33238/ReBECEM.2020.v.4.n.2.24137

Figura 1: Anos do ensino fundamental que são trabalhadas com mais frequência a educação ambiental

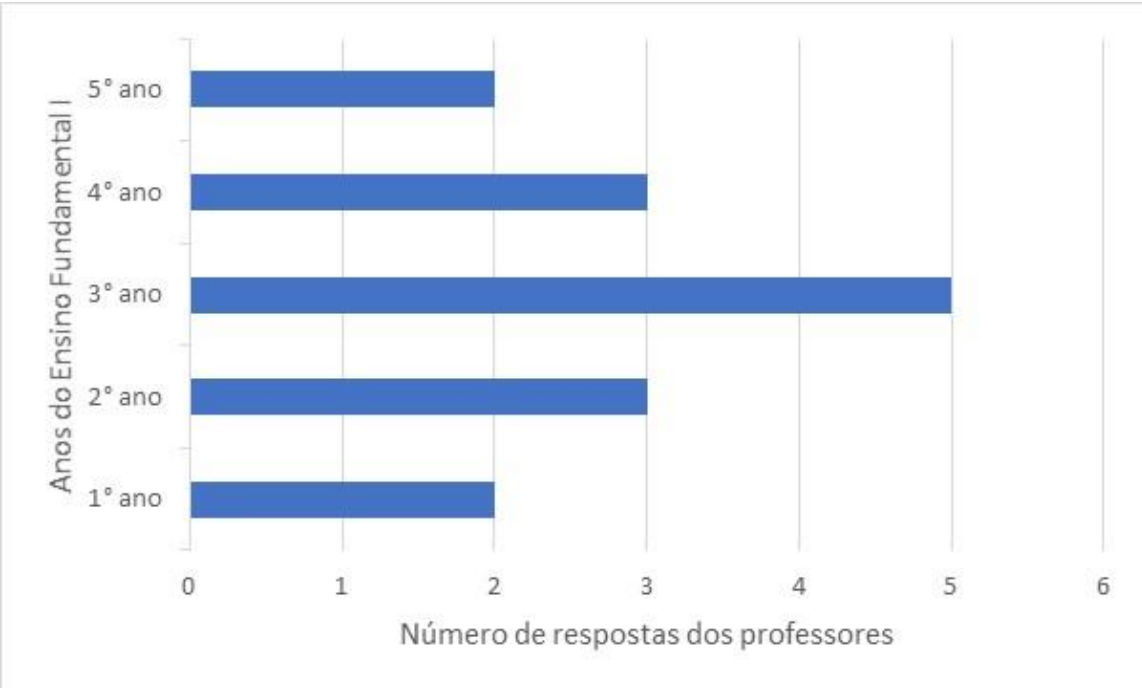

Fonte: dados da pesquisa (2019)

A Figura 2 ilustra os resultados dos questionamentos feitos sobre a interdisciplinaridade nas ações de EA desenvolvidas pelos professores. Dos professores entrevistados, três não responderam à questão, enquanto dois responderam de forma afirmativa, dizendo que fazem tentativas de abordar os temas em conjunto com outras disciplinas em projetos envolvendo diferentes professores, e dois responderam que não houve nenhuma tentativa de ação interdisciplinar ao trabalhar os temas relacionados à EA.

Figura 2: Realização de alguma atividade voltada a educação ambiental juntamente com outras disciplinas

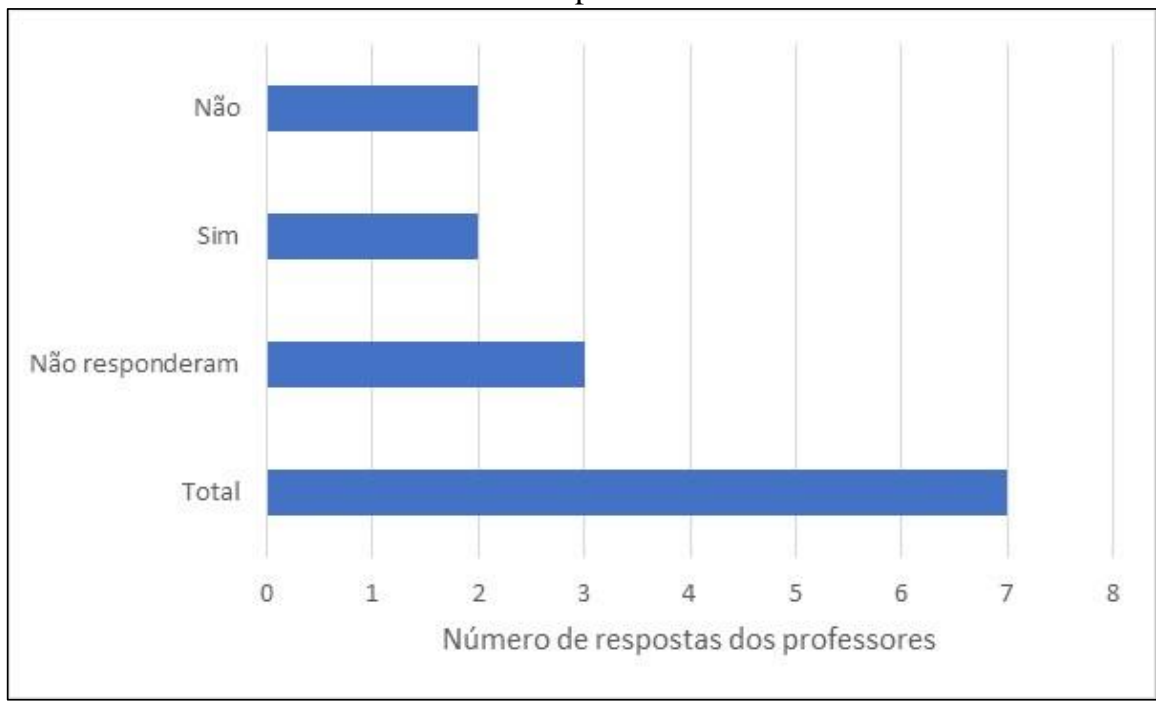

Fonte: dados da pesquisa (2019) 
DOI: https://doi.org/10.33238/ReBECEM.2020.v.4.n.2.24137

Segundo a PNEA, a EA deve estar presente em todas as disciplinas, sendo trabalhada de forma interdisciplinar (PRONEA, 2014). Contudo, a interdisciplinaridade é um grande desafio, pois o esforço de professores sozinhos não é suficiente. A interdisciplinaridade deve ser uma iniciativa institucional das escolas, devendo ser construída durante os períodos de planejamento. Contudo, como visto anteriormente, nem sempre as atividades de EA são inseridas nesses períodos.

A Figura 3 demonstra o envolvimento de diferentes setores nas ações de EA desenvolvidas nas escolas pesquisadas. Segundo Silva (2009), a aprendizagem dos conteúdos referentes à EA será mais significativa se estiver relacionada com situações da vida real da escola e da comunidade ao seu entorno. Para que tudo isso se concretize a escola necessita de apoio e auxílio nas atividades. Isso está exposto no Art. $3^{\circ}$ da PNEA, o qual incumbe ao Poder Público, às instituições e à comunidade em geral promover a EA. Algumas ações nesse sentindo foram verificadas nas escolas analisadas. Nestas, as atividades de EA são geralmente realizadas em parceria com outras instituições, sendo elas: a Prefeitura Municipal, por meio da Secretaria Municipal do Meio Ambiente; empresas, tais como a Itaipu Binacional, por meio do projeto Cultivando Água Boa; Universidades e Associações, tais como a Associação dos Agentes Ambientais.

Figura 3: Instituições parceiras no desenvolvimento de atividades de EA nas escolas pesquisadas

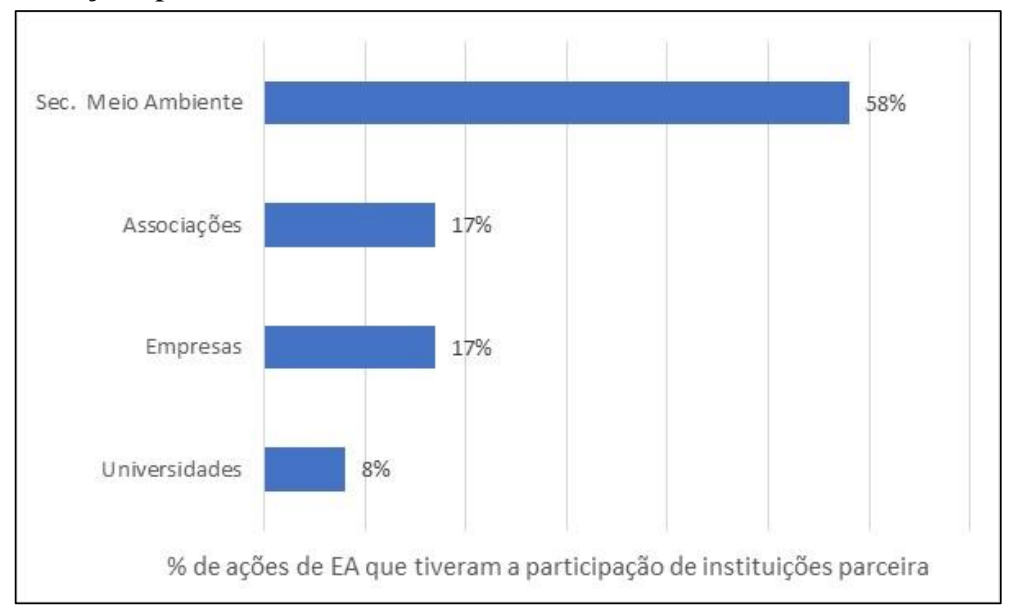

Fonte: dados da pesquisa (2019)

Baseando-se nos dados da Figura 3, é possível constatar que a Secretaria Municipal do Meio Ambiente é a principal parceira no desenvolvimento e organização das atividades de EA em todas as escolas, auxiliando em $58 \%$ das ações, enquanto outras instituições como a Itaipu Binacional e Universidades foram citadas em 29\% e 14\% das ações, respectivamente. Com base nesses dados, é possível perceber que não há o 


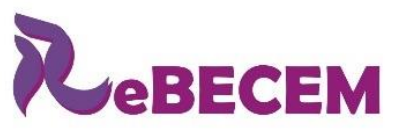

Revista Brasileira de Educação em

Ciências e Educação Matemática

DOI: https://doi.org/10.33238/ReBECEM.2020.v.4.n.2.24137

interesse de muitas instituições externas e empresas privadas em desenvolver atividades voltadas à EA, deixando a responsabilidade a cargo das escolas e da prefeitura.

De acordo com o Programa Nacional de Educação Ambiental (PRONEA, 2014), todas as atividades voltadas à problemática ambiental e para a construção de uma sociedade sustentável, deve envolver uma articulação coordenada entre todos os setores da sociedade. Dessa maneira, é necessário um engajamento entre as escolas e as instituições externas para formar cidadãos responsáveis pelo meio ambiente e pelo uso sustentável dos recursos naturais. Sendo assim, é preciso que empresas, escolas e outras instituições unam forças para ampliar as atividades de EA desenvolvidas nas escolas, de forma a integrar toda a comunidade.

As escolas também possuem a incumbência de integrar suas ações de EA com a comunidade de seu entorno. Nesse quesito, os professores pesquisados afirmaram que $57 \%$ das atividades desenvolvidas são direcionadas a toda comunidade escolar (alunos, professores e funcionários), enquanto $43 \%$ é direcionada apenas para alunos e professores. Nenhuma das ações envolveram a vizinhança da escola e nem os familiares dos alunos. Sendo assim, destacamos a importância de fazer um trabalho amplo, não apenas direcionado aos professores e alunos em exclusividade, mas a todos os ocupantes do espaço escolar e da comunidade a qual a escola pertence, para que se torne uma prática social coletiva (BERMUDEZ; LONGHI, 2008).

A pesquisa também buscou investigar quais os temas ambientais são comumente trabalhados pelos professores. Na Figura 4, é possível observar os temas referentes à EA que foram mais abordados em sala de aula.

É possível perceber na Figura 4 que os temas poluição, reciclagem de lixo, hortas/plantas medicinais e espécies ameaçadas apareceram em 100\% das respostas, sendo o tema poluição abordado com mais frequência. Esses resultados estão de acordo com o que relata Cascino (2000). Esse autor argumenta que apesar de muitos professores trabalharem a problemática ambientalista em sala de aula, as atividades de EA geralmente são voltadas para conscientização restrita, sendo abordadas geralmente na ótica das vertentes Conservacionista e Pragmática. 
DOI: https://doi.org/10.33238/ReBECEM.2020.v.4.n.2.24137

Figura 4: Temas relacionados à EA abordados em sala de aula nas escolas pesquisadas.

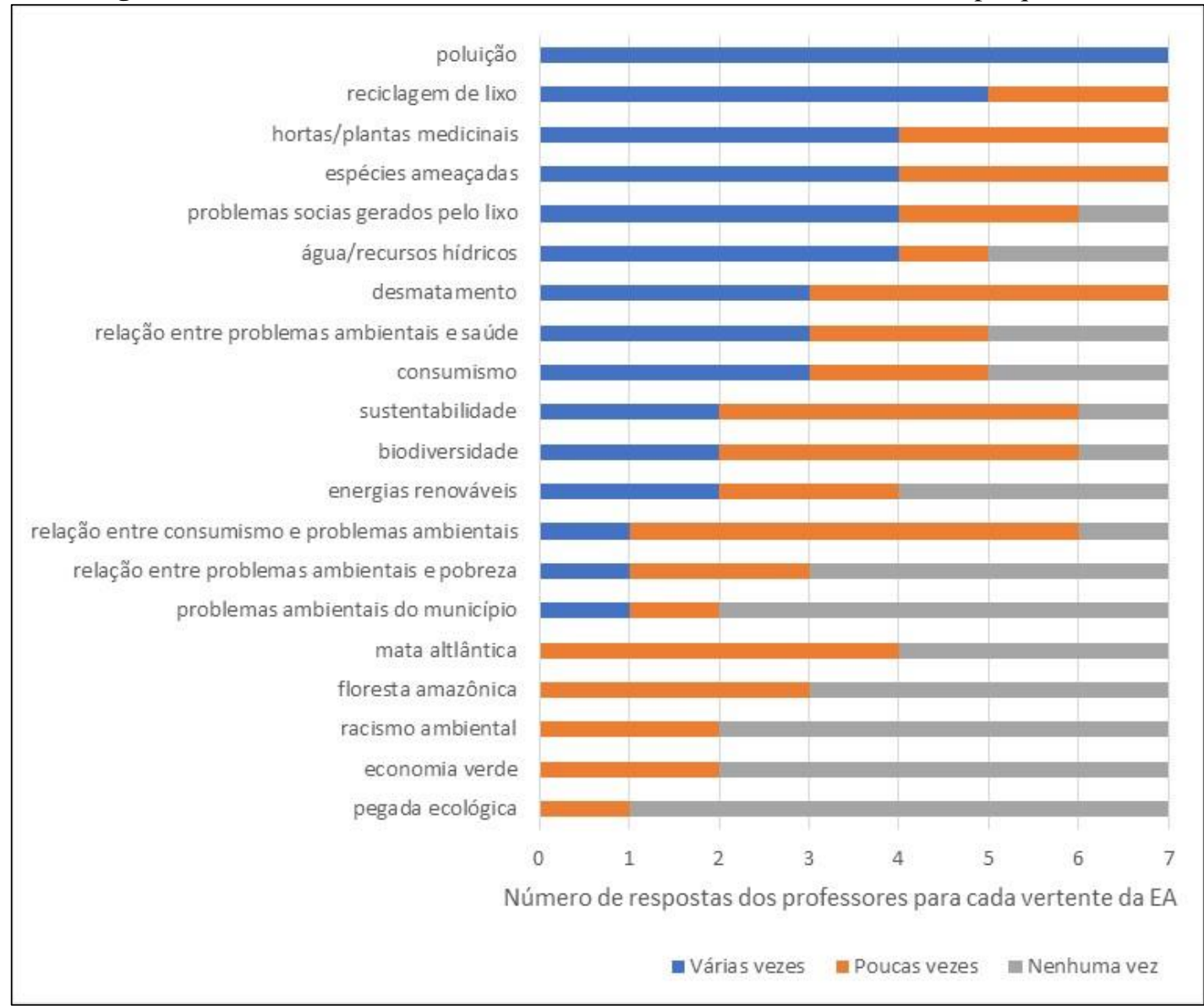

Fonte: dados da pesquisa (2019)

Para entender melhor essa problemática, os temas trabalhados pelos professores entrevistados foram organizados em categorias de acordo com três vertentes da EA (Conservacionista, Pragmática e Crítica), conforme pode ser observado na Tabela 1. Para isso, foram consideradas as definições e objetivos de cada vertente descritos na literatura, bem como o relato dos professores sobre a maneira de como esses temas eram trabalhados em sala de aula. Em seguida, as respostas foram quantificadas e agrupadas para formar a Figura 5.

Tabela 1: Temas abordados nas aulas ou atividades relacionadas à EA agrupados por vertentes da EA

\begin{tabular}{cccc}
\hline $\begin{array}{c}\text { Temas/Vertentes } \\
\text { Vertente Conservacionista }\end{array}$ & Várias vezes & $\begin{array}{c}\text { Respostas } \\
\text { Poucas vezes }\end{array}$ & Nenhuma vez \\
\hline Floresta amazônica & 0 & 3 & 4 \\
Mata atlântica & 0 & 4 & 3 \\
Biodiversidade & 2 & 4 & 1 \\
Desmatamento & 3 & 4 & 0 \\
\hline
\end{tabular}




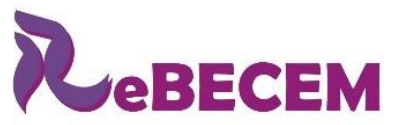

Revista Brasileira de Educação em

Ciências e Educação Matemática

DOI: https://doi.org/10.33238/ReBECEM.2020.v.4.n.2.24137

Água/recursos hídricos

Espécies ameaçadas

4

4

Hortas/plantas medicinais

4

\begin{tabular}{cccc}
\hline Vertente Pragmática & Várias vezes & Poucas vezes & Nenhuma vez \\
\hline Reciclagem de lixo & 5 & 2 & 0 \\
Poluição & 7 & 0 & 0 \\
Pegada ecológica & 0 & 1 & 6 \\
Sustentabilidade & 2 & 4 & 1 \\
Energias renováveis & 2 & 2 & 3 \\
Economia verde & 0 & 2 & 5 \\
Consumismo & 3 & 2 & 2 \\
\hline Vertente Crítica & Várias vezes & Poucas vezes & Nenhuma vez \\
\hline Racismo ambiental & 0 & 2 & 5 \\
Problemas sociais gerados pelo lixo & 4 & 2 & 1 \\
Relação entre problemas ambientais e pobreza & 1 & 2 & 4 \\
Relação entre problemas ambientais e saúde & 3 & 2 & 2 \\
Relação entre consumismo e problemas & 1 & 5 & 5 \\
ambientais & 1 & 1 & 1 \\
Problemas ambientais no município & & & \\
\hline
\end{tabular}

Fonte: dados da pesquisa (2019)

Figura 5: Frequência das abordagens dos temas da EA em relação as vertentes Conservacionista, Crítica e Pragmática

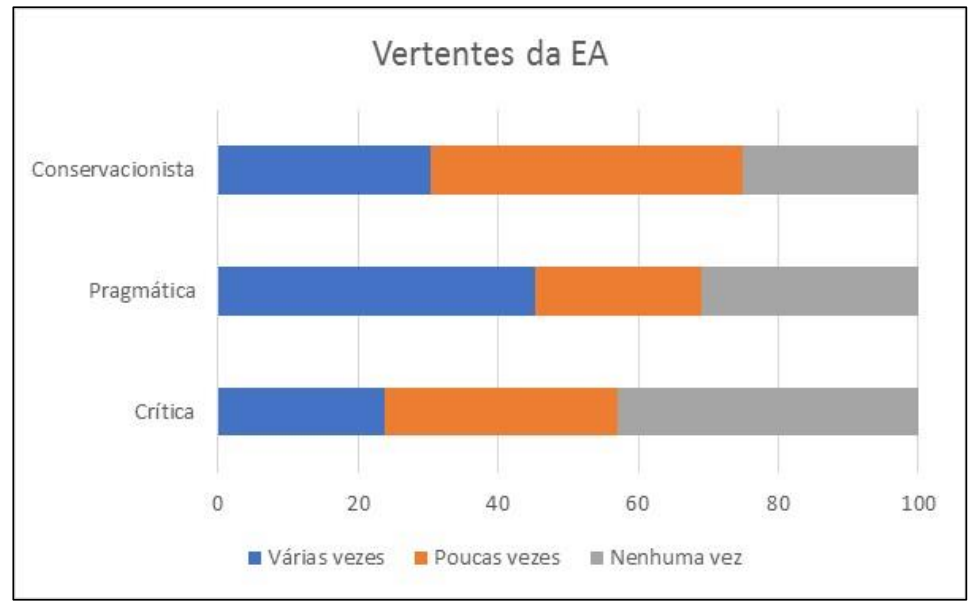

Fonte: dados da pesquisa (2019)

Conforme pode ser observado na Figura 5, as atividades de EA desenvolvidas nas escolas estavam mais relacionadas às vertentes Conservacionista e Pragmática, enquanto a vertente Crítica foi utilizada em poucas das práticas descritas. Segundo Santos e Toschi (2015), a vertente Conservacionista é voltada para atividades relacionadas à natureza, preservação dos recursos naturais e conservação da natureza. Essa vertente também está relacionada com a disciplina de Ciências, pela sua abordagem direcionada para os conteúdos extraídos desse componente curricular. Na vertente Conservacionista não há 
DOI: https://doi.org/10.33238/ReBECEM.2020.v.4.n.2.24137

uma análise crítica e reflexiva das causas econômicas e sociais dos problemas ambientais. Essa vertente pressupõe que a desarmonia homem/natureza reside na maneira individual de como o homem se relaciona com o meio ambiente.

Já a abordagem Pragmática trabalha principalmente os temas consumo sustentável, mudanças climáticas e economia verde. Os adeptos dessa vertente acreditam que a força do Mercado pode resolver os problemas ocorridos e confia na conscientização de consumidores, para que diminuam seu conforto em benefício do meio ambiente e evidencia a participação efetiva das diferentes instâncias da sociedade buscando a participação coletiva. Para alguns autores, a EA Pragmática é considerada uma modificação da Conservacionista, adaptada ao atual contexto socioeconômico e tecnológico da sociedade. Esta vertente, assim como a Conservacionista, não incorpora análises sociais, econômicas, culturais e políticas de forma articulada.

A vertente Crítica aponta que o aprendizado não deve se limitar ao indivíduo, e não deve se basear apenas nos conteúdos escolares, mas sim na vivência em sociedade e do indivíduo com o mundo. A vertente Crítica almeja a formação de cidadãos responsáveis ambientalmente, que se comprometam social, histórico e politicamente a construir sociedades sustentáveis pensando nas futuras gerações (LOUREIRO et al., 2009). Essa vertente está mais de acordo com a PNEA, visto que postula em seu Art. $5^{\circ}$ que são objetivos fundamentais da EA: o desenvolvimento de uma compreensão integrada do meio ambiente em suas múltiplas e complexas relações, envolvendo aspectos ecológicos, psicológicos, legais, políticos, sociais, econômicos, científicos, culturais e éticos; o estímulo e o fortalecimento de uma consciência crítica sobre a problemática ambiental e social.

A vertente Crítica representa a oportunidade de trabalhar com conexões entre diferentes temáticas e dimensões humanas, possibilitando a associação de saberes. $\mathrm{Na}$ abordagem Crítica, o aprendizado e entendimento sobre os problemas ambientais se consegue mediante o olhar sobre o meio ambiente acompanhado de conhecimento e significados socialmente construídos. Estes, por sua vez, são adquiridos pela diversidade cultural e ideológica, pelos conflitos de interesse e temáticas que envolvam discussão e senso crítico para analisar as circunstâncias (JACOBI, 2003). Devido a isso, a vertente Crítica deveria ser utilizada com mais frequência nas atividades de EA desenvolvidas nas escolas.

O predomínio das vertentes Conservacionista e Pragmática também pode ser percebido nas metodologias utilizadas pelos professores para trabalhar a EA em sala de 


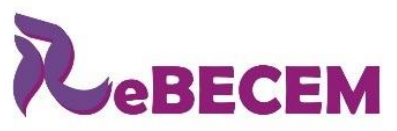

Revista Brasileira de Educação em

Ciências e Educação Matemática

DOI: https://doi.org/10.33238/ReBECEM.2020.v.4.n.2.24137

aula, conforme pode ser observado na Figura 6. Dentre essas práticas, as Aulas expositivas/palestras foram as estratégias didáticas mais utilizadas (39\% dos casos), seguidas das aulas práticas (19\%) e apresentação de vídeos (16\%). Confecção de material informativo (13\%), oficinas (10\%), gincanas (6\%) e apresentações artísticas (3\%), foram práticas pedagógicas menos utilizadas (Figura 6).

Figura 6. Práticas pedagógicas comumente utilizadas nas ações de EA desenvolvidas nas escolas

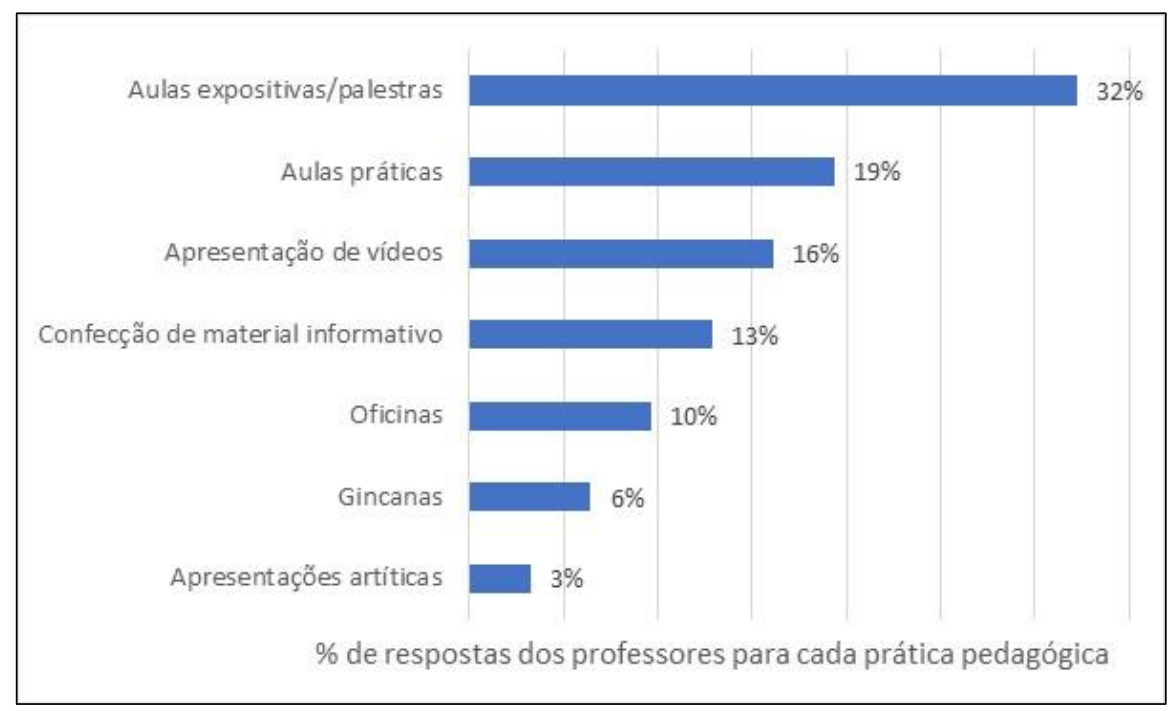

Fonte: dados da pesquisa (2019)

No geral, as aulas expositivas são trabalhadas apenas como forma de transmissão de informações sobre problemas ambientais. Contudo, para Lopes (2012), a exposição de conceitos da EA pode ser trabalhada com a metodologia de aula expositiva dialogada. Esta deve contar com a participação dos alunos por meio de levantamentos dos conhecimentos prévios como ponto de início. Desta maneira, o professor acaba incentivando seus alunos a questionar, discutir e interpretar o material de estudo de acordo com as situações reais expostas. A chave essencial dessa estratégia é o diálogo, pois favorece a análise crítica, produzindo novos conhecimentos e propõe aos alunos uma maior interação com seu meio ambiente e problemas ambientais. Assim, podemos entender que a aula expositiva dialogada pode despertar a atenção dos alunos e facilitar o entendimento do assunto à medida que estimula a construção de aprendizados mais significativos (LOPES, 2012).

As aulas práticas também foram bastante aplicadas pelos professores. As aulas práticas são fundamentais, pois auxiliam no desenvolvimento de conceitos científicos, permitem aos alunos identificar e abordar o mundo em que vivem, buscando respostas mais complexas (LUNETTA, 1991). Servem também como uma estratégia de auxílio ao 


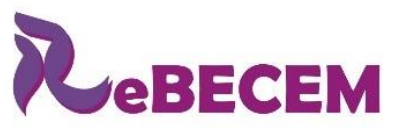

Revista Brasileira de Educação em

Ciências e Educação Matemática

DOI: https://doi.org/10.33238/ReBECEM.2020.v.4.n.2.24137

professor ao retomar assuntos já abordados, construindo uma nova visão sobre o tema. Quando os alunos entendem um conteúdo e se sentem capazes de refletir sobre determinada situação, possibilita a exposição de suas ideias e opiniões, auxiliando na busca de resultados concretos. Contudo, as aulas práticas relacionadas à EA foram, em sua maioria, voltadas para atividades de datas comemorativas, visitas a áreas de preservação, atividades de coleta e separação de resíduos sólidos, trabalhos com materiais recicláveis e cultivo de hortas. Todas essas práticas estão voltadas principalmente para as vertentes Conservacionista e Pragmática. Essas práticas possuem sua importância, mas são necessárias metodologias formadoras do senso crítico, nas quais o aluno possa realmente analisar os problemas ambientais que estão em sua volta e propor soluções.

O trabalho desenvolvido com a coleta de lixo é uma metodologia que tem como objetivo evitar desperdício de matéria-prima e estimular a reciclagem de forma mais racional de gerir os resíduos sólidos urbanos, auxiliando na sensibilização dos alunos quanto à produção de lixo e seu descarte correto. Segundo Felix (2007), a reciclagem em sua essência, é uma forma de educar e fortalecer nas pessoas o vínculo afetivo e preocupado com o meio ambiente, demostrando atitudes e o poder de cada um para modificar o meio em que vivem. Já as atividades relacionadas com hortas podem ser uma boa opção, pois além de promover a alimentação saudável, estimula mudanças no comportamento familiar e diminui o espaço dos industrializados na escola (TURANO; ALMEIDA, 1999).

As oficinas e gincanas juntas somam $16 \%$ das práticas pedagógicas utilizadas para trabalhar a EA. As oficinas trabalhadas pelos professores foram: artesanato com o lixo reciclável e reciclagem de óleo de cozinha. Da forma como foram trabalhadas pelos professores, essas práticas estavam voltadas principalmente para a vertente Pragmática. Porém, se forem bem empregadas, essas práticas podem ajudar no desenvolvimento do senso crítico, pois podem se tornar uma forma de construir conhecimento a partir da açãoreflexão-ação, proporcionando a oportunidade de os alunos vivenciarem situações concretas e significativas com base no sentir/pensar/agir com o intuito pedagógico. Vieira e Volquind (2002) conceituam as oficinas como sendo um tempo e um espaço de aprendizagem, um contato ativo de transformação entre o aluno e objeto, buscando alternativas, aproximando o aluno pelo interesse próprio.

Já as gincanas focavam a recolha de lixo, desenhos referentes a temas ambientais e na arte com recicláveis, evidenciando a presença das vertentes Conservacionista e Pragmática. Gincana é uma atividade com finalidade lúdica com propriedades de jogo, 


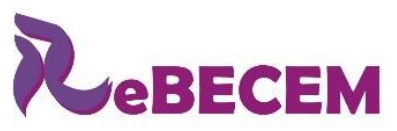

Revista Brasileira de Educação em

Ciências e Educação Matemática

DOI: https://doi.org/10.33238/ReBECEM.2020.v.4.n.2.24137

uma ação livre que tem a capacidade de envolver os jogadores de maneira intensa. Por ser lúdica acaba promovendo uma metodologia em que potencializa a prática pedagógica no processo de ensino aprendizagem do aluno em qualquer tipo de atividades relacionada, até mesmo na área da EA (RESQUE; HAYASHI, 2018). Contudo, assim como as oficinas, as gincanas devem estar associadas a questões que levem à reflexão e ao desenvolvimento do pensamento crítico. E, principalmente, as gincanas devem desenvolver o ato de cooperação e não de competição entre os participantes.

\section{Conclusões}

A presente pesquisa mostra que a EA é trabalhada nos anos iniciais do Ensino Fundamental por meio de atividades variadas. A maioria dessas atividades utiliza como base as vertentes Conservacionista e Pragmática da EA, sendo poucas as atividades pautadas na vertente Crítica. Foi possível perceber iniciativas de trabalhos interdisciplinares, por meio das atividades desenvolvidas pelos professores em sala de aula, mas estas foram pouco expressivas na maioria das respostas. Houve também pouco envolvimento da comunidade externa nas ações de EA desenvolvidas. Diante dos resultados, pode-se concluir que as ações de EA desenvolvidas nas escolas pesquisadas atendem parcialmente aos pressupostos da PNEA, sendo necessário ampliar a inserção dessas atividades no período de planejamento dos professores e o desenvolvimento de práticas que estimulem de forma mais efetiva o senso crítico voltado para as questões ambientais. O que pode ser viabilizado a partir de cursos de formação continuada dos professores e estudos e debates acerca da inserção da EA no currículo de cada instituição e seu devido contexto.

\section{Referências}

AVILA, A. M.; LINGNAU, R. Crise ambiental, ensino de biologia e educação ambiental: uma abordagem crítica. Revista Monografias Ambientais, Santa Maria, v. 14, p. 137-150. 2015.

BERMUDEZ, G.; LONGHI, A. L. La educación ambiental y la ecologia como ciência: uma discusión necesaria para la enseñanza. Revista Electrónica de Enseñanza de lãs Ciências, Vigo, v. 7, n. 2, p. 275-297. 2008.

BONZI, R. S. Meio século de Primavera silenciosa: um livro que mudou o mundo.

Desenvolvimento e Meio Ambiente, Curitiba, v. 28, p.207-215. 2013.

BRASIL. Parâmetros Curriculares Nacionais: Ciências Naturais. Secretaria de Educação Fundamental - MEC/SEF. Brasília, DF, 136p. 1998. 
DOI: https://doi.org/10.33238/ReBECEM.2020.v.4.n.2.24137

BRASIL. Lei n 9.795, de 27 de abr. de 1999. Política Nacional de Educação Ambiental. Brasília, DF, 1999.

BRYMAN, A. Quantitative and qualitative research: further reflections on their integration. In: BRANNEN, J. (ed.). Mixing Methods: quantitative and qualitative research. Aldershot: Avebury, p. 57-80. 1992.

CAMPOS, D.B. Educação ambiental na educação infantil: conhecimentos, valores e participação política no eixo de trabalho "natureza e sociedade. In: ENCONTRO PESQUISA EM EDUCAÇÃO AMBIENTAL, 8, 2015, Rio de Janeiro, Anais... Rio de Janeiro: UFRJ / UFRRJ / UNIRIO / FFCLRP-USP 2015. p. 1-11.

CASCINO, F. Educação ambiental: princípios história formação de professores. São Paulo: Senac, 2000.

DIAS, de C.; BOMFIM, A. M. do. A “Teoria do Fazer” em Educação Ambiental Crítica: uma reflexão construída em contraposição à Educação Ambiental Conservacionista. In:

ENCONTRO NACIONAL DE PESQUISA EM EDUCAÇÃO EM CIÊNCIAS, 8, 2011, Campinas. Atas... Campinas: ABRAPEC, 2011. p. 1-9.

DIAS, G. F. Educação ambiental: princípios e práticas. 5. ed. São Paulo: Gaia, 1998.

FELIX, A. Z. R. Coleta seletiva em ambiente escolar. Revista Eletrônica do Mestrado em Educação Ambiental, Rio Grande, v.18, p. 56-71, jan.jun. 2007.

FERREIRA, J. E.; PEREIRA, S. G. D. C.; BORGES, S. A Importância da Educação Ambiental no Ensino Fundamental. Revista Brasileira de Educação e Cultura, São Gotardo, v. 7, p. 104119. 2013.

FLICK, U. Introdução à pesquisa qualitativa. 3.ed. Porto Alegre: Artmed, 2009.

GIL, A. C. Como elaborar projetos de pesquisa. 4.ed. São Paulo: Atlas, 2002.

GUIMARÃES, R.; FONTOURA, Y. Desenvolvimento sustentável na Rio+ 20: discursos, avanços, retrocessos e novas perspectivas. Cadernos Ebape, Rio de Janeiro, v. 10, n. 3, p. 508532. 2012.

IBGE. Santa Helena. IBGE Cidades. 2019. Disponível em https://cidades.ibge.gov.br/brasil/pr/santa-helena/panorama. Acessado em: 21 de out. 2019.

JACOBI, P. Educação ambiental, cidadania e sustentabilidade. Caderno de Pesquisa, São Paulo, v.118, p.189-205. 2003.

LOPES, T. O. Aula expositiva dialogada e aula simulada: comparação entre estratégias de ensino na graduação em enfermagem. 2012. Dissertação (Mestrado em Gerenciamento em Enfermagem.) - Escola de Enfermagem da Universidade de São Paulo, Universidade de São Paulo, São Paulo, 2012.

LOUREIRO, C. F. B. et al. Contribuições da teoria marxista para a educação ambiental crítica. Cadernos Cedes, Campinas, v. 29, n. 77, p. 81-97, 2009.

LUNETTA, V. N. Actividades práticas no ensino da Ciência. Revista Portuguesa de Educação, Braga, v. 2, n. 1, p. 81-90, 1991. 
DOI: https://doi.org/10.33238/ReBECEM.2020.v.4.n.2.24137

MEDEIROS, A. B. et al. A Importância da educação ambiental na escola nas séries iniciais. Revista Faculdade Montes Belos, São Luís de Montes Belos, v. 4, n.1, p. 1-17, 2011.

OLIVEIRA, M. C. Plano de aula: ferramenta pedagógica da prática docente. Pergaminho, Patos de Minas, v. 2, p. 121-129, nov. 2011.

POTT, C. M.; ESTRELA, C. C. Histórico ambiental: desastres ambientais e o despertar de um novo pensamento. Estudos Avançados, São Paulo, v. 31, n.89, p. 271-283, 2017.

PRONEA. Educação Ambiental por um Brasil sustentável. 4. ed. Ministério do Meio Ambiente. Secretaria de Articulação Institucional e Cidadania Ambiental Departamento de Educação Ambiental, Brasília: MMA e MEC, 2014.

REIS, L. C. L.; SEMÊDO, L. T. A. S.; GOMES, R. C. Conscientização Ambiental: da Educação Formal a Não Formal. Revista Fluminense de Extensão Universitária, Vassouras, v. 2, n.1, p.47-60, 2012.

RESQUE, D. B.; HAYASHI, S. N. Gincana ambiental como fonte inspiradora de preservação na comunidade flexeira situada na resex marinha de Tracuateua-PA. Ambiente \& Educação, Rio Grande, v. 23, n. 2, p. 426-437, 2018.

SANTOS, J. de A.; TOSCHI, M. S. Vertentes da Educação Ambiental: da conservacionista à crítica. Journal of Social, Technological and Environmental Science, Anápolis, v.4, n.2, p. 241-250, 2015.

SAWYER, D. Economia verde e/ou desenvolvimento sustentável? Política Ambiental. Economia verde: desafios e oportunidades, Belo Horizonte, n. 8, p. 36-42, 2011.

SILVA, J. R. N. Educação Ambiental no Contexto do Projeto Político-Pedagógico de Duas Escolas Estaduais de Manaus-AM. In: CONGRESSO DE PESQUISA E INOVAÇÃO DA REDE NORTE E NORDESTE DE EDUCAÇÃO TECNOLÓGICA, 4., 2009, Belém. Anais... Belém: Instituto Federal do Pará, 2009. p. 1-5.

SILVA, C. E. M.; TEIXEIRA, S. F. Educação Ambiental no Brasil: reflexões a partir da Década da Educação para o Desenvolvimento Sustentável das Nações Unidas (2005-2014). Educação (UFSM), Santa Maria, v. 44, p. 76-1-20, 2019.

TRAJBER, R.; SORRENTINO, M. Políticas de Educação Ambiental do Órgão Gestor. In: MELLO, S.S.; TRAJBER, R. (org.). Vamos Cuidar do Brasil: conceitos e práticas em Educação Ambiental na escola. Brasília-DF: MEC, MMA, UNESCO, 2007, p. 13-22.

TURANO, W.; ALMEIDA, C.C.C. A Didática na Educação Nutricional. In: GOUVEIA, E.L.C. Nutrição, Saúde e Comunidade. 2. ed. Rio de Janeiro: Revinter, 1999. p. 107-128.

VIEIRA, E.; VOLQUIND, L. Oficinas de ensino: O quê? Por quê? Como? 4. ed. Porto Alegre: Edipucrs, 2002.

Recebido em: 27 de fevereiro de 2020

Aceito em: 20 de julho de 2020 